\title{
The New Journal
}

\author{
Martha C. Pennington
}

This is the inaugural issue of a journal, Writing \& Pedagogy, that seeks to provide a new forum for discussion and dissemination of knowledge focused on both writing and the teaching of writing. It is innovative in being both international in scope and in spanning across all levels of education, from K-12 through doctoral level. The journal aims to provide information and stimulate conversations that can advance the theory and practice of writing pedagogy in first- and second-language environments by revealing similarities and differences in the practices and concerns regarding writing and the teaching of writing across different contexts and educational systems. The journal solicits submissions in the categories of essays, research reports, pedagogical reflections, discussions of technology, and book reviews. Although the primary focus is on the teaching of English writing within formal education, the journal welcomes articles on writing outside of English education, such as the teaching of writing in other languages, the writing needs of specific workplace contexts, and issues of a theoretical or practical nature involving the nature of writing or research on writing.

The intention of the journal for the first four volumes (2009-2012) will be to publish twice yearly, in Spring and Autumn, with the first issue each year being an "open topic" issue and the second being a "special topic" issue. This first issue, which can serve as a model of what we are aiming for in our future open topic issues, includes a Featured Essay, two Research Matters articles, three Reflections on Practice articles, two From the e-Sphere articles, and two New Books reviews.

\section{Affiliation}




\section{Editor's Perspective on Volume 1, Number 1}

The Featured Essay for Volume 1, "Representation, Ideology, and the Form of the Essay," is by Olivia Y. Archibald. In this essay, Archibald distinguishes between the traditions of Michel de Montaigne and Sir Francis Bacon in the essay genre, arguing against the privileging in academic writing in general and the first-year writing course in particular of the Baconian tradition over the Montaignian approach. Whereas in Montaigne's essais, the author speaks directly to the reader in narrating a train of thought, in the Baconian essay which many academicians and writing teachers today would think of as the academic essay - the author's thinking process and personhood are entirely hidden. The individual self, having moved entirely off-stage, is no longer profiled within the essay as an actual person but becomes instead the Voice of Authority, the Voice of Reason.

Rather than an individual writer's personal narration of thinking-in-progress, in the dominating Baconian tradition, academic writing becomes all information, a trend which the linguist Michael Halliday has connected to the rise of science in the Western world (see, e.g., Halliday, 1993; Halliday and Martin, 1993). As Halliday has shown, this trend has moved written language increasingly away from describing events in time, with an emphasis on verbs, and into a more abstract realm of generalizations and facts, in which most of meaning is compacted into complex noun constructions. The Baconian orientation, which is aligned with the traditions of logical positivism and "scientific objectivity" that have dominated Western scholarship in the modern era, is in sharp contrast with that of Montaigne's essays, which, as Archibald emphasizes, are discursive, subjective, and meandering. In contrast to the objective ideal of a straight-line trajectory for modern (Western) academic writing - as portrayed for instance in a much-discussed essay by Robert Kaplan (Kaplan, 1966) - the Montaignian essay wanders in time and conceptual space from one mental focus to another. It also wonders as the author, approaching new topics of exploration and maintaining an interaction with the reader, asks questions both rhetorical and real. Centuries after Montaigne and Bacon, the tendency of the writer to wander and wonder, as the great Virginia Woolf advocated and practiced herself (e.g. in discussing the place of women writers, and many other things, in "A room of one's own," Woolf, 1929), having been banished from the genre of the academic essay, may find a more welcoming reception in the contemporary genre of creative nonfiction.

The two articles in the Research Matters section of the journal report studies carried out in nearly the same number of classrooms which are both founded on notions of teachers working together to spread good practices. The first is a report of an ongoing pedagogical development project implemented by Paula

\section{eevinoxonline}


Lee Kristmanson, Joseph Dicks, and Josée Le Bouthillier in 21 classes in New Brunswick, Canada; the second is a comparative investigation conducted by Candace Roberts in 22 classes in the Tampa Bay, Florida, area. In "Pedagogical Applications of a Second Language Writing Model at Elementary and Middle School Levels," Kristmanson, Dicks, and LeBoutillier introduce a model for the teaching of writing (ECRI) that has been applied in the bilingual EnglishFrench context of New Brunswick, Canada. The development of the model took place within a context of school-university partnership and teachers' Professional Learning Communities (PLCs), and was based on a review of best practices and teacher tryouts and modification over a multi-year period. In the first phase of this pedagogical research, the model was trialed and developed in elementary school classes, and then, in the second phase, it was further developed and elaborated in middle school classes. The ECRI model comprises a series of steps, beginning with setting a goal and target for writing, followed by modeled writing, shared writing, consideration of the elements of good writing, and independent writing. Additional input is provided on use of tools that support writing, readings in the relevant genre, and oral tasks for linguistic and cognitive support of writing. The authors describe the key features of the model and teachers' implementations of and responses to it in French and English classes at the two levels of education.

The teachers' reception of the model was positive, and specific best practices associated with it that were noted by the research team in classroom observations and by the teachers themselves in their reflections and discussions within the PLCs are described. These include vocabulary-building and modeling of sentence structure related to genre features, support for balanced literacy and the development of fluency and accuracy in oral and written language, use of graphic organizers as visual models for writing, and conferencing as support for drafting. Areas of teachers' attention and priorities in the context of the new writing model are also described, involving connections between speaking and writing; student motivation; a scaffolded, project-based approach to teaching writing; and, among the elementary school students, a sense of belonging to a writing community. The ECRI model, synthesizing best practices from the writing literature with those in evidence in specific classrooms, and adapting to circumstances arising during trials at different levels of education, is an example of a university-schools initiative in which teachers were intimately involved in developing and implementing an innovation within their own classroom contexts and communities of practice. The report of the project demonstrates the value of the two-way flow of information in action research facilitated by university researchers and carried out in partnership with groups of teachers who provide a supportive context for systematic tryouts, adjustments, and reflections on classroom content, process, and outcomes.

\section{eevinoxonline}


Roberts' research, "Professional Development and High-Stakes Testing: Disparate Influences on Student Writing Performance," makes a worthwhile contribution to the teaching community in the United States and internationally in introducing the National Writing Project to those who may not be familiar with it and adding her findings to the growing list of investigations suggesting its effectiveness in spreading good practice in the teaching of writing. Her paper also raises some issues around the kind of state-mandated high-stakes testing which, though late in coming to the United States, is common almost universally at K-12 level worldwide. Roberts' investigation supports the value of the National Writing Project (NWP), a federally funded initiative with multiple sites (over 200 to date) in every state of the U.S. and in Puerto Rico and the Virgin Islands that has been spreading good practice for the teaching of writing. The NWP approach is a teachers-teaching-teachers model using summer institutes, workshops, and other national, regional, and local activities (such as the Success in First-Year Composition conference and monthly Freewrite Nights sponsored by the Georgia Southern University affiliate of the project). Roberts' article makes an important contribution to research on the effectiveness of teachers' participation in the NWP for achieving outcomes in student writing performance, based on a sample of student writing assessments in schools in the Tampa Bay area of Florida. In a study in which individual NWP teacher participants at elementary, middle school, and high school levels were individually matched with a control group of teachers who had similar characteristics but who had not participated in the NWP, Roberts found evidence of greater improvement from the beginning of the school year to the end in the writing of the students of the NWP teacher group as contrasted with the writing of the students of the control teacher group. The difference was particularly noticeable for elementary level and, based on participant interviews, may have occurred outside the context of the state high-stakes test, which both the NWP and the control group teachers felt made it difficult for them to teach according to their best practices.

Roberts' results, which she places within a discussion of the potentially negative effects of high-stakes testing on writing teachers and their teaching practices, are further confirmation of a review by a technique of "metasynthesis" of 49 qualitative investigations on the effects of high-stakes testing on K-12 teaching across the United States ( $\mathrm{Au}, 2007)$. The overall finding is that highstakes testing, as intended by policy makers, "exerts significant amounts of control over the content, knowledge forms, and pedagogies at the classroom level" (Au, 2007: 264), but in ways which, in the majority of cases, are not positive. In the words of $\mathrm{Au}(2007: 264)$, "the tests have the predominant effect of narrowing curricular content to those subjects included in the tests, resulting in the increased fragmentation of knowledge forms into bits and pieces

\section{equinoxonline}


learned for the sake of the tests themselves, and compelling teachers to use more lecture-based, teacher-centered pedagogies." Thus, while high-stakes testing may have the intended effects of focusing teaching and learning, increasing on-task behavior, and driving classroom process towards testable outcomes, it does so in ways which tend to limit the quality and quantity of knowledge that students are exposed to and to pressure teachers away from learner-centered best practices. The stated belief of the NWP in the value of teachers leading teachers and education more generally, as captured in statements such as "Teachers at every level - from kindergarten through college - are the agents of reform" and "Collectively, teacher-leaders are our greatest resource for educational reform” (http://www.nwp.org/cs/public/print/doc/about.csp), cannot easily be squared with the top-down imposition of state-mandated tests which teachers report make it hard for them to apply the best practices they have learned from other educators. Of particular note in relation to Roberts' research and the mounting list of studies demonstrating its positive impacts on writing is that the National Writing Project, whose core grant is from the U.S. Department of Education, appears to be at odds with the high-stakes testing movement that is a main focus of that very same department.

The Reflections on Practice section of the journal seeks to place good practices within a context of published literature on the teaching of writing as well as writing theory and research. In this first issue, Michael A. Pemberton writes about the state of the art of writing centers in "A Finger in Every Pie: The Expanding Role of Writing Centers in Writing Instruction." Pemberton begins by briefly reviewing the over one hundred year history of writing centers, which now provide one-on-one instruction and support for literacy at universities and in many high schools, middle schools, and elementary schools in the United States and a number of other countries. Pemberton describes writing centers in relation to first-year composition and writing across the curriculum initiatives involving satellite centers, workshops, online resources, tutors, and writing center fellows. He also enumerates ways in which writing centers can make links with audiences off-campus and the community beyond the physical buildings and grounds of educational institutions. Pemberton articulates the developing functions of writing centers within and outside of formal education, suggesting an expanding role in the future for increasingly "distributed" writing centers to contribute to broadening literacy in new collaborative relationships and physical and virtual spaces.

Mark Warschauer, in "Learning to Write in the Laptop Classroom," summarizes the findings of a study on the effects of introducing laptop computers into ten elementary, middle school, and high school classrooms in California and Maine. Based on surveys, classroom observations, and interviews across the studied school sites, Warschauer and his research team determined that the

\section{eevinoxonline}


laptop computers were mainly used for writing-related functions of composing, editing, and finding information online. Students made frequent use of graphic organizers in their pre-writing and made heavy use of the computer and its "scaffolding tools" such as spellcheckers, grammar checkers, dictionaries, and thesauruses in drafting their written work. Students made more revision changes to their work in the computer context and shared their work more widely than in a traditional classroom without computers. In addition, three schools used automated writing evaluation software to score students' essays in comparison to essays previously scored by hand. Although the ways in which the computers were used was impacted by the K-12 emphasis on high-stakes testing, Warschauer reports improved integration of writing into instruction and improved writing overall as a result of the introduction of laptop computers into all of the ten schools.

The final Reflections on Practice contribution, that of Ulugbek Nurmukhamedov, "Teacher Feedback on Writing: Considering the Options," compares and contrasts the three feedback modes of pen and paper, computerautomated track changes and commenting, and audio feedback. Starting from a review of literature on writing feedback, Nurmukhamedov offers a balanced approach to his comparison of the three feedback modes, describing the value and strengths of each as well as their limitations. In addition, he offers assessments and comments on the three types of feedback as offered by his own students when they were systematically exposed to them in his writing classes. Nurmukhamedov suggests that teachers can benefit by becoming more aware of the options for giving feedback to their students and by systematically experimenting with different approaches in order to expand their repertoire and best meet the needs of different students who may have different feedback preferences.

The journal introduces a unique, From the e-Sphere section edited by Vance Stevens, who provides an inaugural view, "Writing in the eSphere: Where Connectivity and Literacy Collide," of this important area of attention for writing teachers and their students. Stevens notes the demotivating effects on language learning of behaviorism that lingered in the 1970s, when he first began teaching. However, he soon became aware of the dawning process writing movement and the first instructional uses of computers around the same time and began to see how these two educational movements could reinforce each other and help to implement effective teaching and learning. Stevens discusses how process writing and social writing practices have gradually converged with developing computer and internet technologies to aid writing in transformative ways. For example, blogging and Web 2.0 connect people for social networking, feedback, and publication as part of the writing process at any stage. These are but two of the resources available that can keep writing teachers and students

\section{eevinoxonline}


connected and help them develop not only literacy but also multiliteracy capabilities in print as well as audio and visual media. Yet, as Stevens points out, teachers often lag far behind their students in their knowledge and use of the available technologies, thus suggesting an important role for From the e-Sphere contributions to fulfill.

Elizabeth Hanson-Smith's contribution to From the e-Sphere, "Writing in CyberSpaces," offers a model that updates process writing for online contexts. Hanson-Smith begins with a brief overview of the nature of writing as a process of drafting through multiple stages with meaning taking center stage ahead of grammar and accuracy. She also notes the attention to cognitive approaches to teaching which were aligned with writing in universities starting in the 1980s. She then focuses on the Internet and World Wide Web in connecting learners and classrooms for writing instruction and support. Alongside textbooks, students can develop topics for their writing in online discussion, such as through teaching systems (e.g. Moodle or Blackboard) or other online venues (e.g. Elluminate or $W i Z i Q)$, or by accessing online readings, such as through news services and online encyclopedias. They can be encouraged to write and draft by making use of blogs and wikis, including the features of the advanced wiki, Google Docs. Online tools that aid the writing process are increasingly available, including text checkers and concordancers as well as multimedia Web pages, podcasts, online slideshows, video blogs, and online interviews and collaborations. These may be communicated on a "smart" phone or the Internet phone system. Hanson-Smith references a wealth of resources for using these and other computer and Internet technologies in writing classes, noting that they are "intensely motivating to students. Hanson-Smith concludes with an updating of the model introduced at the outset to include writing in Internet contexts.

Our New Books editor, Laura Valeri, has commissioned reviews from Caren Schnur Neile of David Lazar's edited collection, Truth in Nonfiction, and from Dylan B. Dryer of Elenore Long's Community Literacy and the Rhetoric of Local Publics. Neile centers her review of the Lazar collection on the question of what counts as a reasonable standard of truth for works of nonfiction, noting that the genre of memoir, and the unreliability of memory, raise the most issues around this question. While describing the book as "beautifully written and a pleasure to navigate," Neile notes that many of the authors cover the same ground and wonders whether "some degree of argument among contributors would have made the book more compelling." Dryer's review of Long's book on community literacy suggests the sophistication of this area of literacy studies and the many ways in which students and teachers may be engaged to address problems and explore strategies for public action to raise literacy standards. Of particular interest for this journal is Long's Chapter 9, where she discusses the possibilities for students to "go public" in their coursework by focusing on

\section{eevinoxonline}


community projects. Dryer suggests "[the] book will not only guide novices through this compelling and sometimes contentious field [but] will also enable experts to rethink what they already know and to re-imagine future projects."

\section{References}

$\mathrm{Au}, \mathrm{W}$. (2007) High-stakes testing and curricular control: A qualitative metasynthesis. Educational Researcher 36: 258-67.

Halliday, M. A. K. (1993) New ways of meaning: A challenge to applied linguistics. In M. A. K. Halliday (ed.) Language in a Changing World 1-41. Occasional Paper Number 13. Deakin, Australia: Applied Linguistics Association of Australia.

Halliday, M. A. K. and Martin, J. R. (1993) Writing Science: Literacy and Discursive Power. London: Falmer Press.

Kaplan, R. B. (1966) Cultural thought patterns in intercultural education. Language Learning 16(1): 1-20.

Woolf, V. (1929) A Room of One’s Own. New York: Harcourt, Brace and Company.

\section{Upcoming Issues}

The special topic issues for the first four volumes are:

\section{UPCOMING SPECIAL TOPIC ISSUES}

Vol. 1(2) 2009 Postgraduate Writing In production

Vol. 2(2) 2010 Plagiarism in the Academy In editing

Vol. 3(2) $2011 \quad$ Multiliteracies

Guest Editors: Jim Cummins and Sherry Taylor

Vol. 4(2) 2012 Teaching Creative Writing Guest Editor: Harriet Millan

The issue on Postgraduate Writing is in production, and the Plagiarism in the Academy issue is undergoing editing. The contents and authors of the Multiliteracies issue have been agreed with the Guest Editors, Jim Cummins (Ontario Institute of Studies in Education, University of Toronto) and Sherry Taylor (University of Western Ontario). We are seeking further special topics issues for Volume 5 and beyond, and we are especially interested in the following topics: Teaching Writing in Elementary School, Teaching Writing in Content Areas, Changing Needs for Writing in the Twenty-First Century, Writing 
Assessment, Education and Professional Development of Writing Teachers. These are also topics for which we would welcome individual contributions to the journal in the genres of essay, research, and reflections on practice.

\section{CONTENTS}

Volume 1, number 2 (Autumn 2009) Special Topic: Postgraduate Writing

\section{Research Matters}

Incorporating and Evaluating Voices in a Film Studies Thesis

Using the PhD Thesis Introduction As a Heuristic for Writing a Thesis The Influence of Revision on First Person Pronoun Use in Thesis Writing

\section{Reflections on Practice}

Empowering the Apprentice Academic: Teaching Writing at Postgraduate Level

Teaching Discourse Functions Using a Science Thesis

Caroline Coffin, Open University (UK)

James Donohue, Open University (UK)

Suganthi P. John, University of Birmingham (UK)

Annette Frances Sachtleben, Pat Strauss and Elizabeth Turner, Auckland University of Technology (NZ)

Phil Hubbard, Stanford

University (USA)

\section{From the e-Sphere}

Text Analysis By Computer: Using Free Online Resources to Explore Academic Writing

Semi-Automated Analysis of a Thesis

Ylva Berglund Prytz,

University of Oxford (UK)

Oliver Mason, University of

Birmingham (UK) and Martha

C. Pennington, Georgia Southern

University (USA)

\section{New Books}

Dimitra Koutsantoni, Developing Academic Literacies: Understanding Disciplinary Communities' Culture and Rhetoric

Reviewed by Vladimir Zegarac, University of Bedfordshire (UK) 
Highlights for Volume 2, number 1 (Spring 2010)

\section{Research Matters}

Writing in Late Immersion Biology and History Classes in Hong Kong

Chained and Confused: Teacher Perceptions of Formulaic Writing in a Virtual Classroom

Undergraduate Iranian EFL Learners' Use of Writing Strategies

\section{Reflections on Practice}

Engaging Future Teachers to Reflect on How Reading and Writing Can Change Lives

A Refocused Approach to Writing Instruction

\section{From the e-Sphere}

Writing in a Multiliterate Flat World: Multiliterate Approaches to Writing and Collaboration Through Social Networking

Stella Kong, Hong Kong Institute of Education (Hong Kong)

Amy Alison Lannin and Roy F. Fox, University of Missouri (USA)

Esmael Abdollahzadeh, University of Tehran (Iran)

Maureen P. Hall and Robert P. Waxler, University of Massachusetts at Dartmouth (USA)

Lisa Nazarenko and Gillian Schwarz, University of Vienna (Austria)

Vance Stevens, The Petroleum Institute, Abu Dhabi (UAE)

Volume 2, number 2 (Autumn 2010) Special Topic: Plagiarism in the Academy

\section{Research Matters}

Writing from Sources, Writing from Sentences

Rebecca Moore Howard, Patricia Serviss, and Tanya K. Rodrigue, Syracuse University (USA)

\section{Reflections on Practice}

Positively Addressing Plagiarism and Jane Suzanne Conzett, Margaret MarAcademic Honesty Issues with Second- tin, and Madeleine Mitchell, Xavier Language Writers University (USA)

\section{New Books}

Diane Pecorari, Academic Writing and Plagiarism: a Linguistic Analysis

Reviewed by Virginia LoCastro, University of Florida (USA)

Wendy Sutherland-Smith, Plagiarism, the Internet and Student Learning Reviewed by Miriam Eisenstein Ebsworth, New York University (USA) 